\title{
Brexit and the illegal puppy trade
}

BSAVA members have been told that Brexit may offer an opportunity for the UK government to tackle the animal welfare abuses and zoonotic disease risks resulting from illegal imports of puppies into the UK. John Bonner reports.

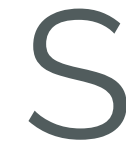
peaking in the Big Issues session at the 2018 Birmingham congress, Dr Paula Boyden, Chief Veterinary Officer with DogsTrust, said that if the UK had remained an EU member it would be difficult to address the failings in the Pet Travel Scheme which have encouraged the puppy trade. But the decision to leave the trading bloc provides the chance to redraft UK legislation to strengthen animal health and welfare controls.

In a series of covert investigations, DogsTrust has been monitoring the growth in the illegal trade in puppies from Eastern Europe since the Pet Travel Scheme (PETS) requirements were relaxed in 2012. After those changes, the numbers of dogs entering the UK under that scheme from Lithuania increased by $780 \%$ and from Hungary by $663 \%$. Undercover filming showed that puppies may travel in vans from Lithuania for up to 30 hours without water or air conditioning "The conditions these puppies have to endure are pretty horrific," she said.

The investigations also gathered evidence of puppies arriving in the UK which originated in third world countries outside the EU where rabies is still endemic and which should therefore be subject to quarantine arrangements. These animals will be travelling without appropriate documentation and often with outright forgeries. Regrettably, there is evidence of veterinary colleagues in the exporting countries actively facilitating this trade by, for example, providing sedatives to keep the puppies quiet during the journey, she said.

Since 2015, DogsTrust has been working with the Department for Environment, Food and Rural Affairs (DEFRA), its Animal and Plant Health Agency and Kent Trading Standards department in a project which aims to disrupt this trade. Puppies found without proper documentation are seized. If the importer refuses to pay the costs of quarantine, ownership passes to DogsTrust which will pay those fees and find new owners when the animal is released.

However, there are many reasons why the chances of detecting a smuggled dog will be slim, she said. Security staff at the ports have other competing demands on their time and usually any visual checks on the animals are likely to be cursory, at best. There are also difficulties in keeping up with the evolving tactics used by importers, who are now sending slightly older animals to reduce the risk of detecting 
illegal imports due to the puppies being below the minimum age for travel. The large sums earned from the trade also encourage importers to employ other methods to avoid detection, such as swapping vehicles at the port terminal.

Dr Boyden said that on leaving the EU, the UK can review the way that the PETS scheme operates and shift the responsibility for checking vehicles away from the carrier companies and back to the government agencies. A system for registering the details held on the microchip is needed; currently, incoming animals are supposed to have been microchipped but there is no central process for accessing the information contained. There should also be a system for logging all animal movements into the UK - it would be vital to know when an animal arrived in the country if there is to be an effective response to the introduction of diseases like rabies, she pointed out.

Another essential step is to introduce sanctions which would be sufficient to deter those seeking to profit from the illegal trade in puppies. "The penalties just aren't there at the moment - there have been just two prosecutions and the fines are such that people can just walk away from them. Compare this to cigarette smuggling for which people can receive jail sentences of up to 7 years - it doesn't make sense," she said.

Dr Boyden reminded colleagues that when the PETS arrangements were changed, the likelihood that rabies could enter the UK increased, as it is clear that a single rabies vaccination may not be fully protective in all dogs. The government should be encouraged to reintroduce the need for a confirmatory blood test and increase the waiting period before travel to bring it into line with the likely incubation period for animals that have already been exposed to the virus.

The UK government should also be reminded that rabies is not the only zoonotic disease threat from imported dogs - the need for treatment against ticks and an extension of the window in which cats and dogs should be treated against tapeworms should also be considered, she said.

Sharon Edwards, an officer with the City of London animal health and welfare service, which is responsible for animals arriving at Heathrow airport, said her colleagues have powers to investigate the animals after they have been imported and rehomed in the UK. This may cause distress in taking animals away from their new family but the responsibility to prevent disease entering the country is much more important, she warned.

Ms Edwards urged veterinary practitioners to report any evidence that an animal has arrived with inaccurate or incomplete documentation. Vets should be suspicious, for example, when the claimed date of birth and the apparent age of the puppy do not match, or when the pet passport appears to have been altered. She even showed examples of animals being presented with 'passports' that those familiar with the language of the exporting country would recognize as just a vaccination certificate.
In her experience, Ms Edwards said some vets have been reluctant to fully cooperate with local authority investigations. But she reminded her audience that the RCVS code of practice allows members to disclose otherwise confidential details under certain circumstances. These are: if animal welfare or the public interest is compromised; when an animal shows signs of abuse; when there is a threat to public health; or in the prevention, detection or prosecution of a crime. Vets must be prepared to aid any investigation by keeping full records on the suspect animal and photocopying any relevant paperwork - "We need vets as our partners, we can't do this job on our own," she said.

Ms Gilly Mendes Ferreira, an inspector with the Scottish Society for the Prevention of Cruelty to Animals, also highlighted the importance of cooperation between different organizations in tackling problems like puppy smuggling, and other criminal activities to which it is often linked.

\section{$4 . \quad$ On leaving the EU, the UK can review the way that the PETS scheme operates and shift the responsibility for checking vehicles away from the carrier companies and back to the government agencies.}

Further to the potential changes in the PETS regulations, her charity was campaigning for legislative measures that would help in the detection and prevention of animal welfare abuses. One of the key priorities of the welfare charities at present was in lobbying for the details of animal cruelty prosecutions to be held on the Police National Computer. Failing that, a suitable alternative step would be to establish an animal offenders register. This would help prevent people convicted of animal welfare offences simply moving to another part of the UK and continuing their activities there, she said

The Scottish SPCA was also actively engaged in education efforts, particularly at school level, to improve understanding of animal welfare issues. As part of this strategy, the Scottish SPCA launched a campaign in April 2018 called 'Say No to Puppy Dealers' to raise awareness of the health and behavioural problems associated with pets supplied through the illegal puppy trade. The charity will be working with other organizations to establish a database of 'trusted traders' to ensure that prospective owners are able to find healthy and properly socialized animals, Ms Mendes Ferreira explained. 